\title{
Cytokinin Application Retains Water Status and Carbohydrate Content of Wheat Genotypes under PEG-6000 Induced Water Deficit
}

\author{
Aparjot Kaur* and S.K. Thind \\ Department of Botany, Punjab Agricultural University, Ludhiana, Punjab, India \\ *Corresponding author
}

\begin{tabular}{|l|}
\hline Ke y w o r d s \\
Leaf water content, \\
$\begin{array}{l}\text { Soluble sugars, } \\
\text { Starch, Cytokinins, } \\
\text { Wheat }\end{array}$ \\
\hline Article Info \\
\hline $\begin{array}{l}\text { Accepted: } \\
\text { 06 July } 2018 \\
\text { Available Online: } \\
\text { 10 August } 2018\end{array}$ \\
\hline
\end{tabular}

A B S T R A C T
Among abiotic stresses drought is one of the most important limiting factor that adversely affect the plant production in the majority of agricultural crops of the world. Presently exogenous application of cytokinins i.e., Kinetin (@ 10, 20 and $40 \mathrm{mg} / \mathrm{L}$ ) and Benzyl adenine(@25 and $50 \mathrm{mg} / \mathrm{L}$ ) was studied on plant Relative leaf water content (RLWC), Water saturation deficit (WSD), relative saturation deficit (RSD) and carbohydrate metabolism (total soluble sugars and starch) content of wheat cultivars under water deficit conditions. PEG-induced (-0.4Mpa) stress significantly decreased the content of RLWC and Starch content in wheat cvs (HD2967, PBW660, WH1105 and PBW658). Exogenous application of both cytokinins \{Kinetin (Kn) and benzyl adenine (BA) \} significantly increased the leaf water content and starch in leaves of wheat seedlings. The total soluble sugars content, WSD and RSD was lesser in control of all selected cultivars and increased significantly under PEG-6000 induced drought stress and significant increase in soluble sugars was further recorded when cytokinins were supplied exogenously. Significant decline in WSD and RSD was observed with the application of both cytokinins. From among the tested levels Kn @ $40 \mathrm{mg} / \mathrm{L}$ and BA @ $50 \mathrm{mg} / \mathrm{L}$ had more pronounced effect. The accumulation of more total soluble sugars and maintenance of starch content leads to more water retention and decline in water deficit of leaf tissue with exogenously applied cytokinins protects the plant from adverse effect of drought.

\section{Introduction}

In India, Wheat (Triticum spp.) is the second most critical winter grain after rice that contributes generously to the National nourishment security by giving over half of the calories to the general population who mainly depend on it. Drought antagonistically influences seed germination, seedling development, plant development, chemical movement and macromolecules. Fresh and dry mass production of crop was lessened because of unfriendly impact of water stress. Drought is one of the commonest and most significant limitations to agricultural production, genuinely influencing crop development, gene expression, distribution, yield and quality. Plant might be influenced by drought whenever of life, however certain stage, for example, germination and seedling development are basic (Shahi et al., 2015). PEG has been utilized frequently as abiotic stress inducer in many reviews to screen drought tolerant germplasm (Almaghrabi 
2012, Ahmad et al., 2013; Jatoi et al., 2014). PEG is a polymer and considered as preferred synthetic over others to prompt water stress artificially. Govindaraj et al., 2010 recorded PEG incited osmotic anxiety is inductee to diminishing cell water potential. Sudden increase in concentration of PEG created a reduction in germination rate, seedling life in certain harvest plants (Khodarahmpour, 2011). Higher water retaining ability during dehydration is an important strategy for acquiring resistance (Lilley and Ludlow 1996; Sgherri et al., 2000). Leaf water content is necessary in maintenance of maximum amount of chlorophyll (Bohrani and Habibi, 1992). The major effects of water stress include, those involving carbohydrate metabolisms, with the accumulation of sugars and a number of other organic solutes. Changes in carbohydrates (type and content) are of particular importance on account of their direct relationships with physiological processes such as photo-synthesis, translocation and respiration. A central role of sugars depend not only on direct involvement in the synthesis of other compounds, production of energy but also on stabilization of membranes (Hoekstra et al., 2001), action as regulators of gene expression and signaling molecules for sugar responsive genes which lead to different physiological responses like defense responses and turgor driven cell expansion.

Cytokinins (CKs) control plant development perspectives and formative procedures, including cell division, apical predominance, chloroplast biogenesis, supplement assembly (nutrient mobilization), leaf senescence, vascular separation, photomorphogenic advancement, shoot separation or differentiation and anthocyanin generation (Mok and Mok, 2001; Davies, 2004). Kinetin is able to crack stress-caused dormancy during germination of seeds (Bozcuk, 1981). Benzyl adenin (BA) inhibited growth during stress, but also overcame the decline in growth rate, shoot/root ratio and internal cytokinin content in a salt-tolerant variety (Kuiper et al., 1990). Chakrabarti and Mukherji, (2003) observed that kinetin acts as an immediate free radical scavenger or it might include in antioxidative mechanism identified with the security of purine breakdown. A conceivable association of qualities in stress reactions is regularly construed from changes in the transcript abundance in response of a given stress trigger. Thus, the main motive to conduct the present investigation was to study the effect of exogenous kinetin and benzyl adenine on carbohydrate metabolism and relative water content of wheat genotypes under drought stress.

\section{Materials and Methods}

Four wheat (Triticum aestivum L.) genotypes viz. HD 2967, WH1105, PBW660 and PBW658 were obtained from Department of Plant Breeding and Genetics. Only healthy seeds were selected for the present investigation. 20 seeds were sown in each petri-plate using the distilled water and incubated at the room temperature $\left(25 \pm 2^{\circ} \mathrm{C}\right)$, relative humidity and light was maintained in incubator. Water deficit was maintained by shifting the seedlings to the petri-plates supplemented with the PEG-6000 (-0.4MPa) solution on $3^{\text {rd }}$ day of sowing and petri-plates treated as control was maintained as such and different treatments (mentioned in figures and tables) of Cytokinins (Kinetin and Benzyl adenine) were given to each petri-plate.

\section{Relative leaf water content (RLWC), water saturation deficit (WSD) and relative saturation deficit (RSD) was calculated as per Weatherley (1950)}

Shoot pieces of equal size were cut and immediately weighed to obtain fresh weight and then saturated by submerging in distilled 
water in petri dishes. After 6 hours, pieces were removed. Surface water was blotted off without putting any pressure and weighed to obtain saturated weight. After drying at $70^{\circ} \mathrm{C}$ for $48 \mathrm{hr}$ dry weight was determined from these data following parameters were calculated.

RLWC $=$ Fresh weight - Dry weight/Saturated weight - Dry weight x 100

WSD = Saturated weight- Fresh weight/ Saturated weight - Dry weight x 100

RSD = Saturated weight- Fresh weight/ Saturated weight x 100

\section{Total soluble sugars}

Total soluble sugars were estimated by method as given by Dubois et al., (1956).

$100 \mathrm{mg}$ of stored dried material was homogenized in $5 \mathrm{ml}$ of 80 percent ethyl alcohol, followed by centrifugation at 5000rpm, followed by another extraction in $3 \mathrm{ml}$ of 80 per cent ethyl alcohol. The final volume of pooled supernatants was adjusted to $10 \mathrm{ml}$ with extraction medium. For estimation, $1 \mathrm{ml}$ of extract was taken in test tube and $1 \mathrm{ml}$ of 5 per cent phenol was added to it. After $5 \mathrm{~min}, 5 \mathrm{ml}$ of reagent $\mathrm{B}$ was added slowly and was stirred continuously. OD of greenish brown colour developed was taken at $490 \mathrm{~nm}$ in spectrophotometer. Distilled was used instead of extract in blank. The quantity of sugars was calculated against the standard curve prepared by using pure glucose (10$100 \mu \mathrm{g} / \mathrm{ml}$ ) and expressed as $\mathrm{mg} \mathrm{g}^{-1}$ dry weight.

\section{Starch content}

Starch was estimated by method as given by McCready et al., (1958).
Fresh tissue sample was homogenized within 80 per cent ethanol. Centrifuged and retained the residue, washed with 80 per cent ethanol 4-5 times to remove all traces of soluble sugars. To confirm it tested last wash for sugars with anthrone reagent. When result was negative added $5 \mathrm{ml}$ of $\mathrm{DW}$ and $6.5 \mathrm{ml}$ of 52 per cent perchloric acid. Kept at $0^{\circ} \mathrm{C}$ for 20 min, centrifuged and retained the extract. Repeated same step 3-4 times and diluted to the desired volume. Took $0.5 \mathrm{ml}$ of diluted extract in a test tube added $4.5 \mathrm{ml}$ of DW and $10 \mathrm{ml}$ of cold anthrone-sulphuric acid reagent (200 mg of anthrone in $100 \mathrm{ml}$ of cold 95 per cent $\mathrm{H}_{2} \mathrm{SO}_{4}$ stored at $0^{\circ} \mathrm{C}$ ) in an ice bath. Heated for $8 \mathrm{~min}$ at $100^{\circ} \mathrm{C}$, cooled to room temperature and read absorbance at $630 \mathrm{~nm}$.

\section{Statistical analysis}

The experimental data were analysed by analysis of variance (ANOVA) using software CPCS1 by Cochran and Cox., (1967).

\section{Results and Discussion}

\section{Relative Leaf Water Content (RLWC)}

All the genotypes had higher RLWC under the controlled conditions as compared to PEG stimulated drought stress as depicted in Figure 1. PEG induced drought stress significantly reduced the RLWC of the studied wheat genotypes but more pronounced effect was shown by genotype PBW658. The genotype HD2967followed by WH1105 attained the higher values of relative leaf water content even under the drought stress. On the other hand the genotype PBW660 (18.46\%) had more percentage decrease (over control) and genotype HD2967 (12.26\%) had lesser percentage decrease over control. Munns et al., (2010) and Boyoumi et al., (2008) also had the similar findings that the Relative water content decreased under the water deficit conditions in wheat. There was significant 
reduction in relative water content under the drought stress as compared to control conditions in Brassica species (Alam et al., 2014).

$\mathrm{Kn} @ 10 \mathrm{mg} / \mathrm{L}$ application on leaves significantly increased the RLWC of the selected genotypes and HD2967 followed by WH1105 possessed higher values as compared with other genotypes. The maximum percentage increase over drought was recorded in genotype PBW660 (7.54\%) followed by HD2967 (6.62\%). All the genotypes had significantly high values than that with the application of $\mathrm{Kn} 20 \mathrm{mg} / \mathrm{L}$. With $\mathrm{Kn}$ 20mg/L the genotype WH1105 followed by HD2967 had higher RLWC and PBW658 had least value. The percentage increase over drought the genotype WH1105 (11.55\%) followed by PBW660 (10.71\%) had high RLWC and PBW658 (8.29\%) had lesser percentage increase.

Beside these two Kn concentrations the higher $\mathrm{Kn}$ concentration i.e. Kn @ 40mg/L there is further increase in RLWC of all the studied wheat genotypes. With that concentration the HD2967 followed by WH1105 acquired the highest RLWC. Genotype PBW658 had lesser leaf water content as compared to other genotypes. The maximum percentage increase was recorded in genotype PBW660 (17.06\%) followed by WH1105 (16.12\%) and lesser percentage increase was recorded in HD2967 (13.54\%). Elliott et al., (1979) observed the cytokinins significantly increased the RWC in Amaranthus.

Different concentrations of BA significantly altered the RLWC of selected wheat genotypes. BA ameliorated the negative effect of PEG induced drought stress. The BA @ $25 \mathrm{mg} / \mathrm{L}$ significantly increased the RLWC but the more pronounced effect was recorded in genotype WH1105 followed by HD2967. Maximum percelntage increase was recorded in PBW658 (10.19\%) followed by WH1105 $(10.01 \%)$. With the application of BA @ $50 \mathrm{mg} / \mathrm{L}$ there was further increase in leaf water content of all the genotypes. The maximum increase was recorded in WH1105 and lesser increase was observed in PBW658. On the hand the maximum percentage increase was observed in PBW660 (15.33\%) followed by WH1105 (15.31\%) and lesser percentage increase was recorded in HD2967 (11.99\%). Saeidi et al., (2015) recorded leaf relative water content decreased with the drought stress in other wheat cultivars. It was recorded that the 20\% PEG solution resulted in decline in relative leaf water content (Sultan et al., 2012). Drought tolerance at cellular level was associated with the ability to accumulate proline and high water level conservation.

\section{Water Saturation Deficit (WSD)}

Figure 2 depicted the water saturation deficit of wheat genotypes under control, stressed and different concentrations of $\mathrm{Kn}$ and BA tested. The PEG induced drought stress significantly increased the WSD of all genotypes as compared to controlled ones. The maximum increase was recorded in PBW658 and genotype WH1105 tends to maintain the lesser WSD even under the drought stress. The maximum percentage increase over control was observed in HD2967 $(52.91 \%)$ followed by WH1105 (49.97\%). Thus, findings also observed that both WSD and RSD increased under the deficit conditions in other wheat genotypes were similar with the findings of the present study (Gupta et al., 2014).

Different concentrations of $\mathrm{Kn}$ significantly reduced the negative effect of PEG and tends to decreased the WSD of all the studied wheat genotypes. With the application of $\mathrm{Kn}$ @ $10 \mathrm{mg} / \mathrm{L}$ the maximum decrease was recorded in WH1105 followed by HD2967. On the other hand the maximum percentage decrease over drought was recorded in genotype 
WH1105 (10.34\%) followed by PBW660 $(8.79 \%)$. After that the Kn @ 20mg/L further decreased the WSD of all studied genotypes but the maximum decrease was observed in wheat genotype again in WH1105 followed by HD2967. Maximum percentage decrease was recorded in WH1105 (21.20\%) followed by PBW658 (18.37\%). With the application of $\mathrm{Kn} @ 40 \mathrm{mg} / \mathrm{L}$ there is further decrease in WSD of different wheat genotypes but the maximum decrease was recorded in again WH1105 followed by HD2967. The maximum decrease in percentage was recorded in HD2967 (52.35\%) followed by WH1105 $(52.33 \%)$ and lesser percentage decrease was recorded in PBW658 (47.95\%). The different concentrations of BA significantly decreased the WSD of presently studied wheat genotypes.

With the application of BA @ 25mg/L the maximum decrease was recorded in WH1105 followed by HD2967 and lesser decrease was observed in PBW658 but the maximum percentage decrease (over drought) was observed in WH1105 (28.52\%) followed by PBW660 (25.76\%) and lesser percentage decrease was recorded in PBW658 $(23.70 \%)$. There was further decrease in WSD of wheat genotypes with the application of BA $50 \mathrm{mg} / \mathrm{L}$, the maximum decrease was recorded in WH1105 and lesser decrease was recorded in PBW658. The maximum percentage decrease was observed in WH1105 (47.03\%) followed by HD2967 (46.40\%) and lesser percentage decrease was recorded in PBW660 (38.57\%).

\section{Relative Saturation Deficit (RSD)}

PEG induced drought stress significantly increased the RSD of all the wheat genotypes as depicted in Figure 3. All genotypes had lower RSD under control conditions. The lower RSD was observed in HD2967 under control as well as under PEG induced drought stress conditions. The genotype PBW658 had high RSD under both the conditions. The more percentage increase was recorded in HD2967 i.e., $56.42 \%$ and followed by PBW660 i.e 44.18\%. Raza et al., 2012 also observed the increase in RSD with the drought stress, on basis of that they categorised the sensitive and tolerant wheat genotypes.

Different $\mathrm{Kn}$ concentrations significantly ameliorated the adverse effect of PEG on all genotypes, $\mathrm{Kn}$ application significantly reduced the RSD of studied genotypes. With $\mathrm{Kn} @ 10 \mathrm{mg} / \mathrm{L}$ the maximum decrease was recorded in WH1105 and lesser decrease was recorded in PBW658. The maximum percentage decrease was recorded in WH1105 $(10.82 \%)$ and lesser was found in HD2967 (5.29\%). Kn @ 20mg/L further decreased the RSD of all genotypes the maximum RSD with that application was recorded again in PBW658 and lesser was observed in HD2967. The percentage decrease was recorded high in WH1105 (31.60\%) followed by HD2967 (24.70\%).

Kn @ 40mg/L had more significant effect in reduction of RSD of all genotypes. PBW658 had more RSD and WH1105 had lesser RSD as compared to all other genotypes with the application of $\mathrm{Kn} 40 \mathrm{mg} / \mathrm{L}$. The percentage decrease was recorded high in WH1105 $(41.70 \%)$ and low percentage decrease was calculated in HD2967 (36.92\%).

BA applications reduced the negative effect of PEG as it significantly decreased the RSD of all studied genotypes. With BA @ 25mg/L the genotype PBW658 followed by PBW660 had higher RSD and HD2967 had lesser RSD as compared to other genotypes. The percentage decrease was found more in HD2967 $(31.39 \%)$ and lesser in PBW660. BA @ $50 \mathrm{mg} / \mathrm{L}$, further decreased the RSD of genotypes. The maximum percentage decrease was recorded in PBW660 (40.70\%) and lesser was observed in PBW658 (28.27\%). 
Fig.1 Effect of different concentrations of Kn (10, 20 and 40mg/L) and BA (25 and 50mg/L) on relative leaf water content (RLWC) at 10 DAS in wheat under PEG induced drought stress.

$$
\mathrm{V}=1.230, \mathrm{~T}=1.091, \mathrm{~V} \times \mathrm{T}=2.130
$$

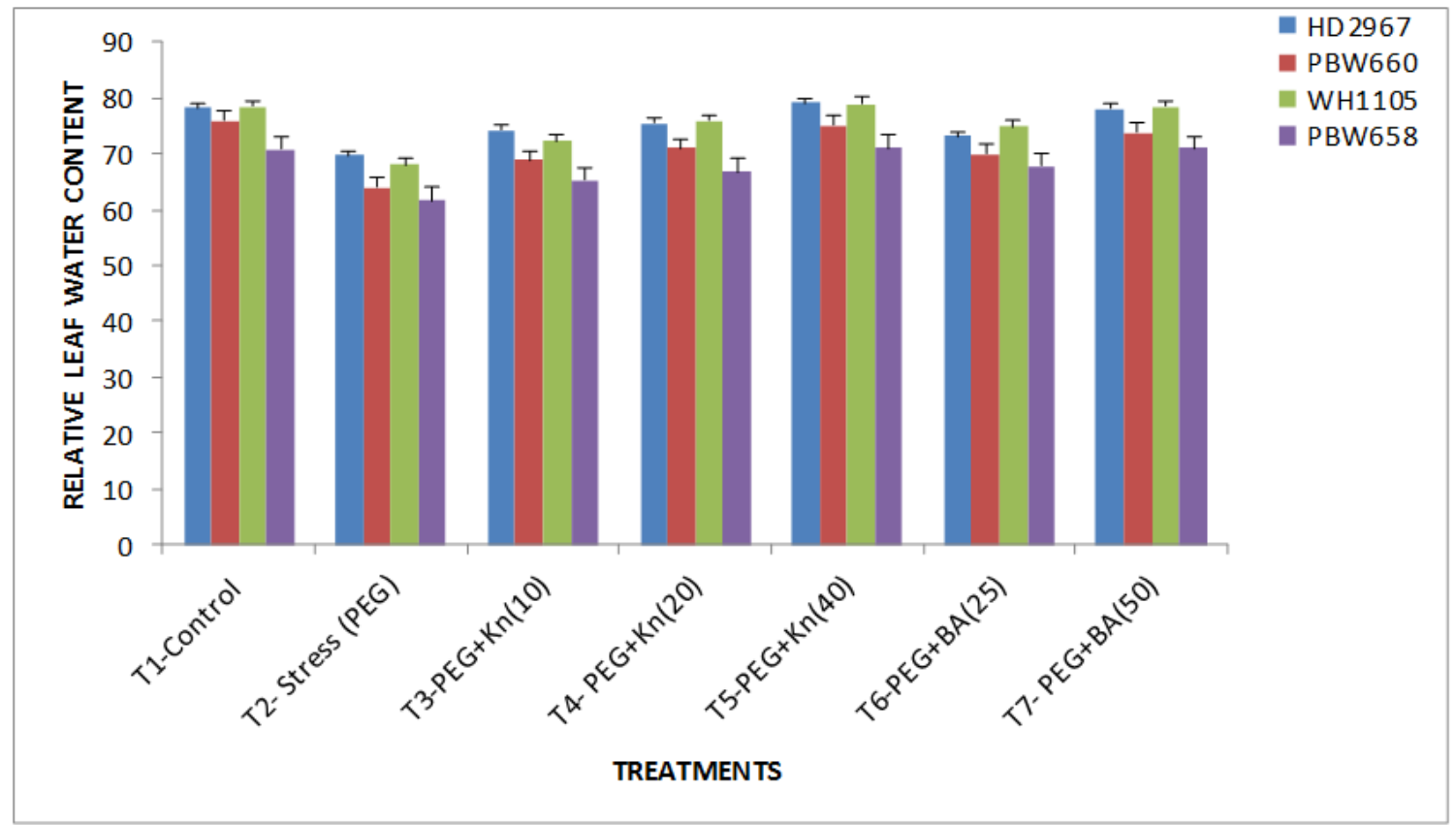

Fig.2 Effect of different concentrations of Kn (10, 20 and 40mg/L) and BA (25 and 50mg/L) on water saturation deficit (WSD) at 10 DAS in wheat under PEG induced drought stress. V=0.434, $\mathrm{T}=0.321, \mathrm{~V} \times \mathrm{T}=1.009$

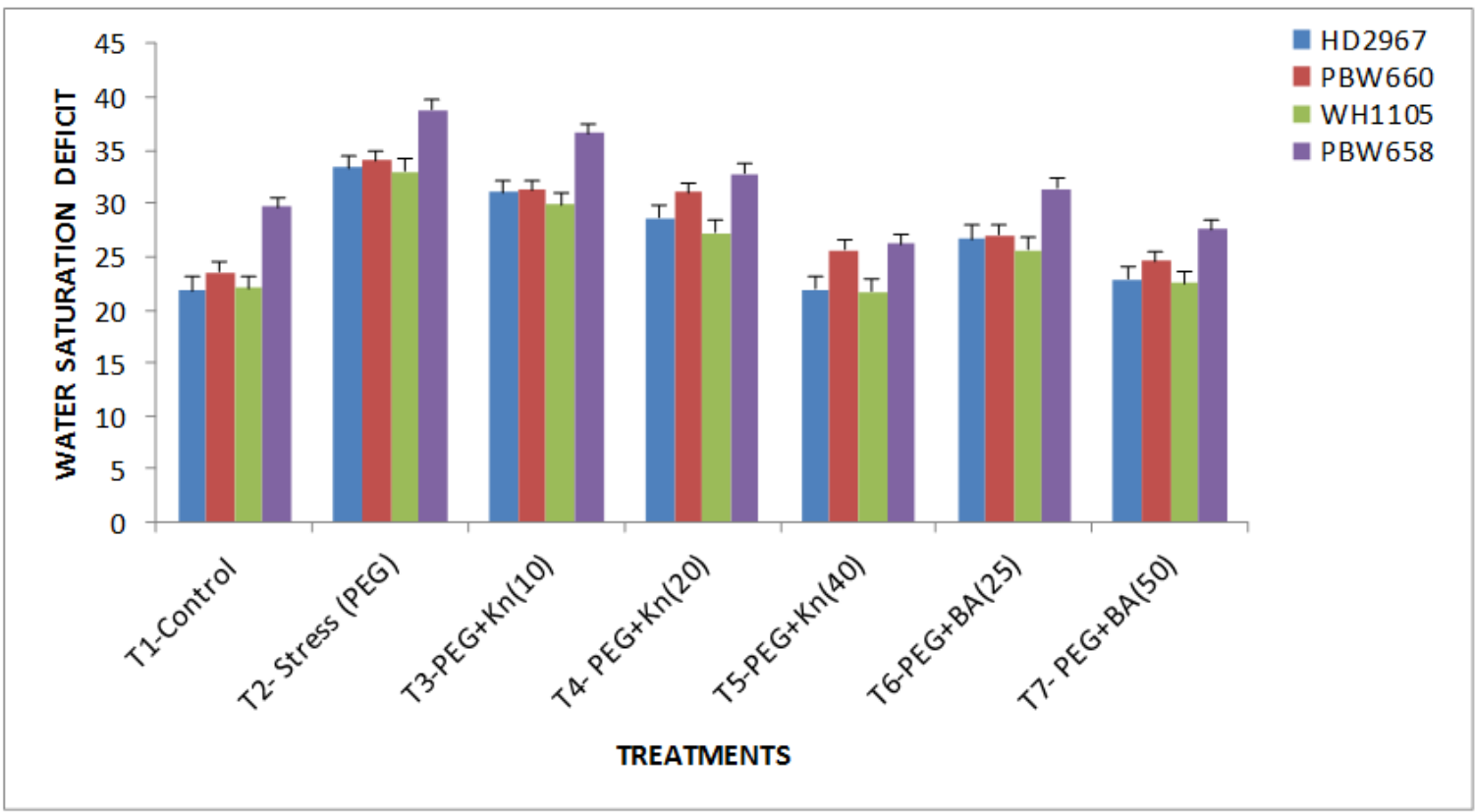


Fig.3 Effect of different concentrations of Kn (10, 20 and 40mg/L) and BA (25 and 50mg/L) on relative saturation deficit (RSD) at $10 \mathrm{DAS}$ in wheat under PEG induced drought stress.

$$
\mathrm{V}=0.293, \mathrm{~T}=0.487, \mathrm{~V} \times \mathrm{T}=1.063
$$

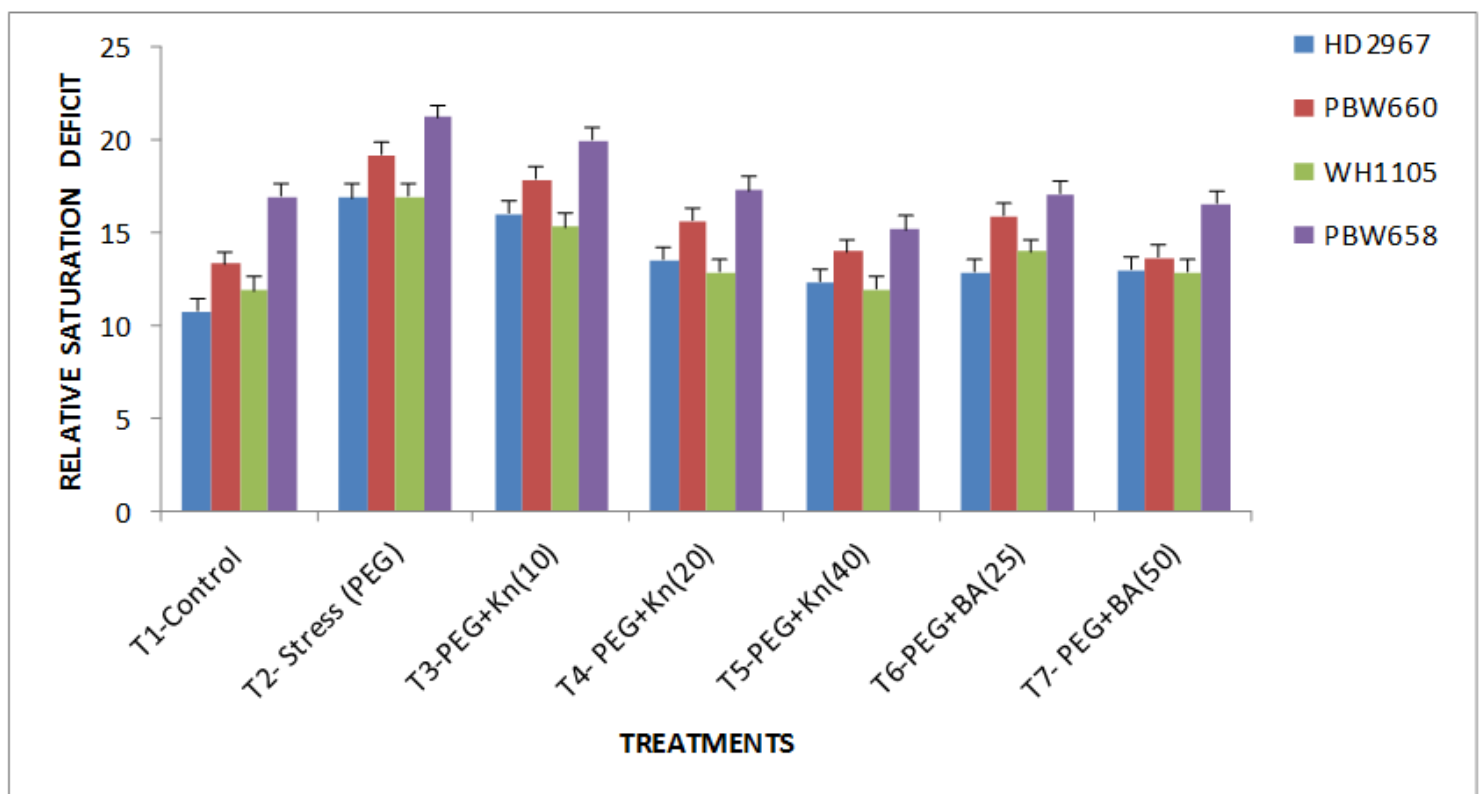

Fig.4 Effect of different concentrations of Kn (10, 20 and 40mg/L) and BA (25 and 50mg/L) on total soluble sugars $\left(\mathrm{mg} \mathrm{gm}^{-1}\right.$ fresh wt) at 10 DAS in wheat under PEG induced drought stress. $\mathrm{V}=0.068, \mathrm{~T}=0.045, \mathrm{~V} \times \mathrm{T}=0.963$

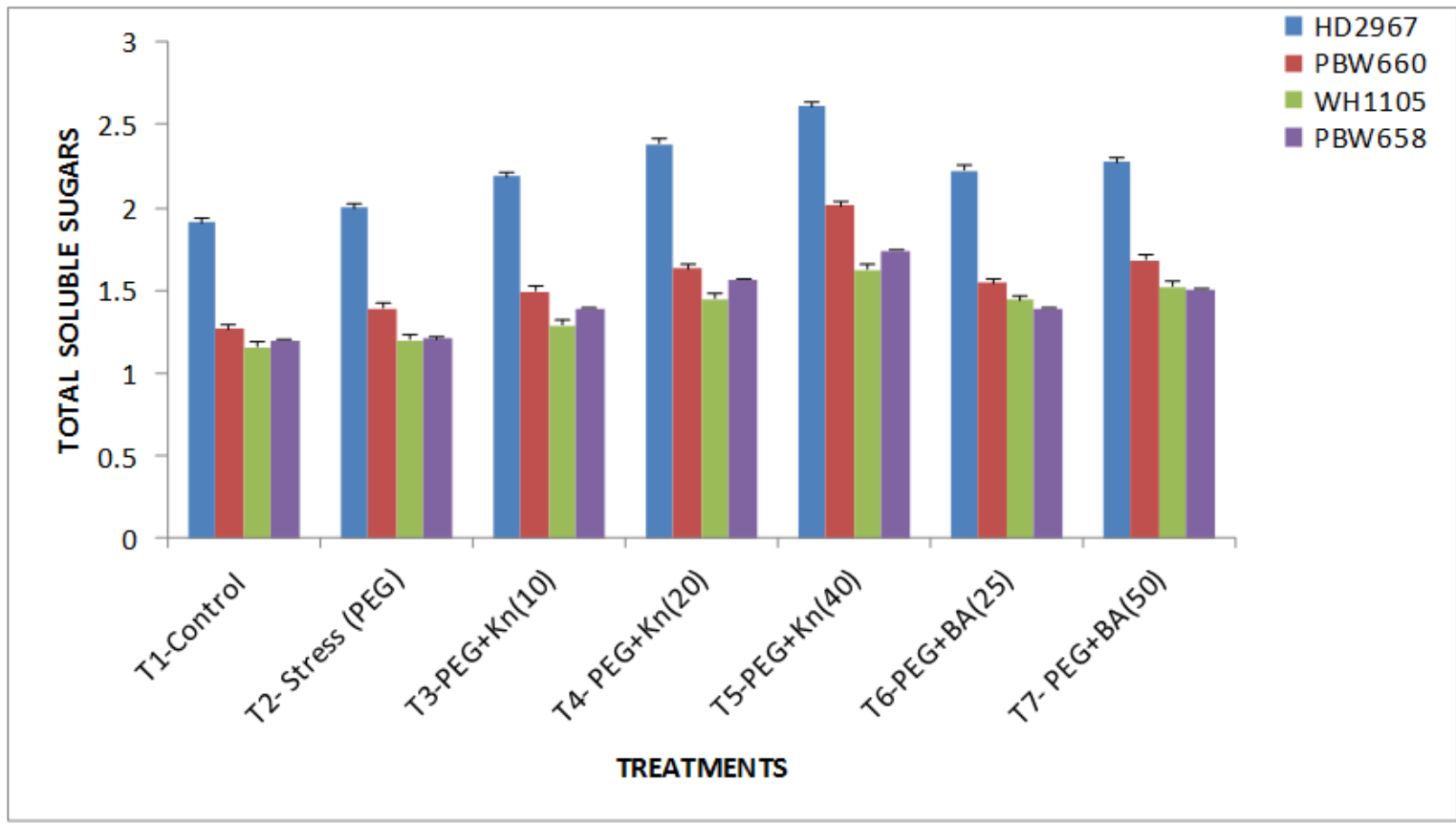


Table.1 Effect of different concentrations of Kn (10, 20 and 40mg/L) and BA (25 and 50mg/L) on Starch content $\left(\mathrm{mg} \mathrm{gm}^{-1}\right.$ fresh wt) at 10 DAS in wheat under PEG induced drought stress

\begin{tabular}{|c|c|c|c|c|}
\hline \multirow{2}{*}{$\begin{array}{l}\text { Treatments } \\
\text { Genotypes }\end{array}$} & \multicolumn{4}{|c|}{ Starch content ( $\mathrm{mg} \mathrm{gm}^{-1}$ fresh wt) } \\
\hline & HD2967 & PBW660 & WH1105 & PBW658 \\
\hline T1-Control & 1.33 & 1.49 & 1.47 & 1.33 \\
\hline $\begin{array}{ll}\text { T2- } & \text { Stress } \\
(\text { PEG }) & \\
\end{array}$ & $\begin{array}{c}1.01 \\
(24.06 \% \downarrow)\end{array}$ & $\begin{array}{c}1.22 \\
(18.12 \% \downarrow)\end{array}$ & $\begin{array}{c}1.11 \\
(24.48 \% \downarrow)\end{array}$ & $\begin{array}{c}0.99 \\
(25.56 \% \downarrow) \\
\end{array}$ \\
\hline T3-PEG+Kn(10) & $\begin{array}{c}1.09 \\
(7.92 \% \uparrow)\end{array}$ & $\begin{array}{c}1.30 \\
(6.56 \% \uparrow)\end{array}$ & $\begin{array}{c}1.26 \\
(13.51 \% \uparrow)\end{array}$ & $\begin{array}{c}1.12 \\
(13.13 \% \uparrow) \\
\end{array}$ \\
\hline $\begin{array}{l}\text { T4- } \\
\text { PEG+Kn(20) }\end{array}$ & $\begin{array}{c}1.12 \\
(10.89 \% \uparrow)\end{array}$ & $\begin{array}{c}1.34 \\
(9.84 \% \uparrow)\end{array}$ & $\begin{array}{c}1.33 \\
(19.82 \% \uparrow)\end{array}$ & $\begin{array}{c}1.19 \\
(20.20 \% \uparrow)\end{array}$ \\
\hline T5-PEG+Kn(40) & $\begin{array}{c}1.19 \\
(17.82 \% \uparrow)\end{array}$ & $\begin{array}{c}1.44 \\
(18.03 \% \uparrow)\end{array}$ & $\begin{array}{c}1.39 \\
(25.26 \% \uparrow)\end{array}$ & $\begin{array}{c}1.28 \\
(29.29 \% \uparrow)\end{array}$ \\
\hline T6-PEG+BA(25) & $\begin{array}{c}1.11 \\
(9.90 \% \uparrow)\end{array}$ & $\begin{array}{c}1.38 \\
(13.11 \% \uparrow)\end{array}$ & $\begin{array}{c}1.33 \\
(19.82 \% \uparrow)\end{array}$ & $\begin{array}{c}1.20 \\
(21.21 \% \uparrow) \\
\end{array}$ \\
\hline $\begin{array}{l}\text { T7- } \\
\text { PEG+BA(50) }\end{array}$ & $\begin{array}{c}1.18 \\
(16.83 \% \uparrow)\end{array}$ & $\begin{array}{c}1.43 \\
(17.21 \% \uparrow)\end{array}$ & $\begin{array}{c}1.36 \\
(22.52 \% \uparrow)\end{array}$ & $\begin{array}{c}1.25 \\
(26.26 \% \uparrow) \\
\end{array}$ \\
\hline CD 5\% & $\begin{array}{c}\mathrm{V}=0.0389, \mathrm{~T}=0.0475 \\
V \times \mathrm{T}=\mathbf{0 . 9 3 3}\end{array}$ & & & \\
\hline
\end{tabular}

Percentage decrease over control is represented by $\downarrow$ and percentage increase over drought is represented by $\uparrow$.

\section{Total Soluble Sugars (TSS)}

Total soluble sugars were measured from the different wheat seedlings at 10 DAS stage the genotype HD2967 followed by PBW660 had maximum TSS (Fig. 4). There was significant increase in TSS of all wheat genotypes during PEG stimulated drought stress. Genotype HD2967 followed by PBW660 had the more TSS even under the drought stress but the maximum percentage increase (over control) was recorded in HD2967 (10.44\%) followed by PBW660 (10.13\%) and genotype WH1105 had lesser percentage increase i.e., $9.00 \%$. Ibrahim et al., 2016 observed that the soluble sugars acts as osmoprotectants and reducing and total soluble sugars accumulated during the stress conditions as the findings were similar with the observations of present study. Marcinska et al., (2013) also found that the PEG induced drought stress resulted in increase in TSS in wheat seedlings. The less membrane damage was correlated with an increase capacity to accumulate sugars at leaf level during the water stress (Bajji 1999, Bajji 2000c)

Soluble sugars maintained the osmoregulation of the cell during the various stress conditions, an increase in TSS of all seedlings with the application of Kn was reported. With the application of $\mathrm{Kn} @ 10 \mathrm{mg} / \mathrm{L}$ all genotypes showed significant increase in TSS and maximum values were recorded in HD2967 and lesser in WH1105. On the other hand PBW658 (15.31\%) had maximum percentage increase (over drought) and PBW660 (7.05\%) had lesser percentage increase. Foliar application of $\mathrm{Kn} 20 \mathrm{mg} / \mathrm{L}$ there was further increase in TSS of all genotypes and maximum increase was recorded again in HD2967 and lesser increase was observed in WH1105 but the maximum percentage increase was recorded in PBW658 (29.63\%) followed by WH1105 (20.70\%). There was further increase in TSS of all genotypes with the application of $\mathrm{Kn} 40 \mathrm{mg} / \mathrm{L}$ and genotype HD2967 followed by PBW660 
had higher TSS. The maximum percentage increase was recorded in PBW660 (44.42\%) and lesser percentage increase was recorded in HD2967 (30.68\%). Application of plant growth hormones like $\mathrm{Kn}$ were found to be effective to affect physiological reactions of plants under water stress conditions and modify the leaves to grain assimilates transfer through affecting carbohydrates synthesis and grain development Iqbal et al.,(2011). Niakan et al., (2014) recorded the similar results with the present study that the foliar spray of $\mathrm{Kn}$ increased TSS under drought stress. Ratnakar et al., (2013) had similar findings recorded in spinach under salt stress. Like Kn, BA also significantly increased TSS of all seedlings. With the application of BA @ $25 \mathrm{mg} / \mathrm{L}$, HD2967 had higher amount of TSS and PBW658 had lesser TSS. But the percentage increase (over drought) was higher in WH1105 (20.03\%) followed by PBW658 (15.07\%). With higher BA concentration i.e., BA $50 \mathrm{mg} / \mathrm{L}$ there was further increase in TSS content of all studied genotypes. HD2967 followed byPBW660 had maximum content of TSS. On the other hand the maximum percentage increase was recorded in WH1105 (26.96\%) followed by PBW658 (24.92\%).

There have been contradictory reports regarding the effect of moisture stress on sugar accumulation in wheat. Some studies have revealsthat sugar content rose (Munns and Weir, 1981) while others have found that sugar content decreased (Hanson andHitz, 1982) or remained unchanged (Morgan, 1992) during stress conditions. Present study showed increase in the level of sugars under drought stress and consistent with findings by other researchers (Kamil and Losel, 1993).

\section{Starch content}

Table 1 depicts the starch content of studied wheat genotypes at the 10 DAS. All the genotypes acquired the high starch content under the controlled conditions but the PEG induced drought stress significantly reduced the starch content of all genotypes. The genotype PBW660 maintained the high starch content even under the drought stress and PBW658 had low starch content as compared to other genotypes. But the percentage decrease over control was recorded maximum in PBW658 (34.34\%) and minimum in PBW660 (22.13\%). Drought stress significantly reduced the starch content in wheat genotypes was may be due to increased activity of amylase that increased the soluble sugars Radhika and Thind (2013). Starch forms the major component of grain, therefore grain yield reduction is mainly caused by the reduction of starch accumulation (Duffus et al., 1992; Emes et al., 2003). A barleystudy shown that endosperm starch reductions ranged from 0 to $45 \%$ when water was withheld from flowering until harvest, and changes in starch content correlated well with yield (Worch et al., 2011).

Different concentrations of Kn significantly increased the starch content of all studied genotypes. Kn @ 10mg/L significantly increased the starch content of all studied genotypes. The PBW660 followed by WH1105 accumulated the high starch content as compared to other genotypes with $\mathrm{Kn}$ @ $10 \mathrm{mg} / \mathrm{L}$. The maximum percentage increase over drought was recorded in WH1105 followed by PBW658 and these were $13.51 \%$ and $13.13 \%$ respectively. With Kn @ 20mg/L there was again significant increase in starch content of all genotypes. Maximum accumulation of starch content was recorded in PBW660 and that is followed by WH1105 and genotype HD2967 had least starch content with that concentration of $\mathrm{Kn}$. The maximum percentage increase with that concentration of Kn was recorded in PBW658 $(20.20 \%)$ and followed by WH1105 (19.82\%).Kn @ 40mg/L further significantly increased the starch of all genotypes. 
PBW660 had high and HD2967 had low starch content. Maximum percentage increase was observed in PBW658 followed by WH1105 these were $29.29 \%$ and $25.26 \%$ respectively.BA application increased the starch content of wheat seedlings. As similar in $\mathrm{Kn}$ concentrations the genotype PBW660 followed by WH1105 acquired the high starch content with both BA applications i.e BA@25mg/L and BA@ 50mg/L. With BA@ $25 \mathrm{mg} / \mathrm{L}$ the maximum percentage increase over drought was observed in PBW658 (21.21\%) followed by WH1105 (19.82\%) and least percentage increase was recorded in HD2967 (9.90\%). The genotype PBW658 again had maximum percentage increase i.e $26.26 \%$ as compared to other genotypes with BA @ 50mg/L and HD2967 (16.83\%) had lower percentage increase. BAP application significantly resulted in increase in starch accumulation in wheat genotypes as recorded by Radhika and Thind (2013).

It can be concluded from the present study that the exogenous application of cytokinins (Kinetin and BA) increased the total soluble sugar and starch content. These metabolites act as the osmoprotectants (serve as osmoticum) and tend to retain the leaf turgor (water content) of wheat genotypes under drought stress.

\section{Acknowledgment}

First author is highly thankful to INSPIRE FELLOWSHIP funded by Department of Science and Technology, New Delhi, INDIA, for providing financial support for research work.

\section{References}

Ahamd, M., Shabbir, G., Minhas, M. N., and Shah, M. K. N. (2013). Identification of Drought Tolerant Wheat Genotype based on Seedling. Trait J Agric., 29: 21-27.

Alam, M. M., Nahar, K., Hasanuzzaman, M. and Fujita, M. (2014).Trehalose induced drought stress tolerance: A comparative study among different Brassica species. Plant Omics J., 7: 271-283.

Almaghrabi, O. A. (2012). Impact of drought stress on germination and seedling growth parameters of some wheat cultivars. Life Sci J., 9: 590-598.

Bajji, M. (1999).Etude des mécanismes de résistance au stress hydrique chez le blédur (Triticum durum Desf.): Caractèrisation de cultivars différant par leursniveaux de résistance á la sécheresseet de variants somaclonauxsélectionnés in vitro. $\mathrm{PhD}$ Dissertation, Universitécatholique de Louvain, Belgium.

Bajji, M. Lutts, S. and Kinet, J. M. (2000c). Resistance to water stress in durum wheat: Comparison of cell and whole seedling behaviours. In: Royo C, Nachit M M, Di Fonzo N and Araus J L (eds), Durum wheat improvement in the Mediterranean region: New challenges. Options Méditerranéennes, pp. 22-34.

Bayoumi, T. Y., Eid, M. H., and Metwali, E. M. (2008).Application of physiological and biochemical indices as a screening technique for drought tolerance in wheat genotypes. Afr J Biotechnol., 7: 2341-2352.

Bohrani, M. and Habibi, N. (1992).Physiology of plants and their cells. Translation. Chamran University Publication.

Bozcuk, S. (1981). Effect of kinetin and salinity on germination of tomato, barley and cotton seeds. Ann Bot., 48: 81-84.

Chakrabarti, N. Mukherji, S. (2003). Alleviation of $\mathrm{NaCl}$ stress by pretreatment with phytohormones in 
Vigna radiata. Biol Plantarum., 46: 58994.

Cochran, W. G., and Cox, G. M. (1967).Experimental design. John Wiley and Sons Ltd., England.

Davies, P. J. (2004). Plant hormones: biosynthesis, signal transduction, action. Kluwer Academic Press, the Netherlands.

Dubois, M., Gilles, K. A., Hamilton, J. K., Rebers, P.A and Smith, F. (1956). Colorimetric method for determination of sugars and related substances. Anal Chem 28: 350-356.

Duffus, C. M. (2003). Control of starch biosynthesis in developing cereal grains. Biochemical Society Transactions, 20: 13-18.

Elliott, D. C. (1979). Analysis of variability in the Amaranthusbetacyanin assay for cytokinins. Plant Physiol63: 274-276.

Emes, M. J., Bowsher, C. G., Hedley, C. Hedley, C. Burrell, M. M., Scrase-Field, E. S. E., Tetlow, I. J. (2003). Starch synthesis and carbon partitioning in developing endosperm. Journal of Experiental Botany54: 569-575.

Govindaraj, M., ShanmugaSundaram, P., Sumathi, P.and Muthiah, A. R. (2010). Simple, rapid and cost effective screening method for drought resistant breeding in pearl millet. Electron. $J$ Plant Breed 1: 590-599.

Gupta, N., Thind, S. K., and Bains, N. S. (2014). Glycine betaine application modifies biochemical attributes of osmotic adjustment in drought stressed wheat. Plant Growth Regul. 72: 221228.

Hanson, A.D., and Hitz, W.D. (1982). Metabolic responses of plant water deficit. Ann. Rev. Plant Physiol. 33: 163-203.

Hoekstra, F. A., Golovina, E. A., and Buitink, J. (2001). Mechanisms of plant desiccation tolerance. Trends $\mathrm{Pl}$ Sci6:
431-438.

Ibrahim, H. A., and Abdellatif, Y. M. R. (2016). Effect of maltose and trehalose on growth, yield and some biochemical components of wheat plant under water stress. Annals AgrilSci., 61(2): 267-274.

Iqbal, N.Rahat, N.Iqbal, M. Khan, R.Asim, M. and Khan, N. A. (2011). Role of gibberellins in regulation of source-sink relations under optimal and limiting environmental conditions.CurrSci7: 998-1007.

Jatoi, S. A., Latif, M. M., Arif, M., Ahson, M., Khan, A. and Siddiqui, S. U. (2014). Comparative Assessment of Wheat Landraces against Polyethylene Glycol Simulated Drought Stress. Sci Tech Dev33: 1-6.

Kamil, A. and Losel, D.M. (1993). Carbohydrates and water status in wheat plant under water stress. New Phytol.125: 605-614.

Khodarahmpour, Z. (2011). Effect of drought stress induced by polyethylene glycol (PEG) on germination indices in corn (Zea mays L.) hybrids. Afr $J$ Biotechnol10: 18222-18227.

Kuiper, D., Schuit, J. and Kuiper, P. J. C. (1990). Actual cytokinin concentrations in plant tissue as an indicator for salt resistance in cereals. Plant Soil123: 243-250.

Lilley, J. M., and Ludlow, M. M. (1996). Expression of osmotic adjustment and dehydration tolerance in diverse rice lines. Field Crop Res48: 185-197.

Marcińska, I. Czyczyło-Mysza, I. Skrzypek, E. Grzesiak, M. Janowiak, F. and Filek, M. (2013). Alleviation of osmotic stress effects by exogenous application of salicylic or abscisic acid on wheat seedlings. Int $\quad J \quad$ MolSci 14: 1317113193.

McCready, R. M., Guggolz, J.Silviera, V. and Owens, S. (1958). Determination of starch and amylase in vegetables. Ann 
Chem22: 1156-1158.

Mok, D. W., and Mok, M. C. (2001). Cytokinin metabolism and action. Annu Rev Plant Physiol Plant Mol Biol., 52:89-118.

Morgan, J.M. (1992). Osmotic components and properties associated with. Genotypic differences in osmoregulation in wheat. Aust. J. Plant Physiol. 19:67-76.

Munns, R. and Weir, R. (1981). Contribution of sugars to osmotic adjustment in elongating and expanded zones of wheat leaves during moderate water deficit at two light levels. Aust. J. PlantPhysiol. 8: 93-105.

Munns, R., James, R. A., Sirault, X. R. R., Furbank, R. T., and Jones, H. G. (2010). New phenotyping methods for screening wheat and barley for beneficial responses to water deficit. $J$ Exptl Bot., 61: 3499-3507.

Niakan, M. and Ahmadi, A. (2014). 'Effects of foliar spraying kinetin on growth parameters and photosynthesis of tomato under different levels of drought stress'. Iranian J Plant Physiol., 4(2): 939-947.

Radhika and Thind, S. K. (2013). Biochemical variation as influenced by benzylaminopurine application in wheat genotypes under variable water deficit conditions. IIOABJ., 4: 10-16.

Ratnakar, A. and Rai, A. (2013). Alleviation of the Effects of $\mathrm{NaCl}$ Salinity in Spinach (Spinacia oleracea L. var. All Green) Using Plant Growth Regulators. J Stress PhysiolBiochem, 9: 122-128.

Raza, M. A. S., Saleem, M. F., Khan, I. H., Jamil, M., Ijaz, M., Khan, M. A.
(2012).Evaluating the drought stress tolerance efficiency of wheat (Triticum aestivum L.) cultivars. Russian J Agril Socio-Econ Sci., 12: 41-46.

Saeidi, M. and Abdoli, M. (2015).Effect of Drought Stress during Grain Filling on Yield and Its Components, Gas Exchange Variables, and Some Physiological Traits of Wheat Cultivars. J AgrSci., 17: 885-898.

Sgherri, C. L. M., Maffei, M., and NavariIzzo, F. (2000). Antioxidative enzymes in wheat subjected to increasing water deficit and re-watering. $J$ Plant Physiol157: 273-279.

Shahi, Vibhuti, C., Bargali, K. and Bargali, S. S. (2015). How Seed Size and Water stress affect the seed germination and seedling growth in wheat varieties? Curr Agric Res J., 3(1): 6068.

Sultan, M. A. R. F., Hui, L., Yang, L. J., and Xian, Z. H. (2012). Assessment of Drought Tolerance of Some Triticum L. Species through Physiological Indices. Czech J Genet Plant Breed 48: 178-184.

Weatherley, P. E. (1950). Studies in water relations of cotton plants I. The field measurement of water deficit in leaves. New Phytol49: 81-87.

Worch, S. Rajesh, K., Harshavardhan, V. T., Pietsch, C. Korzun, V. Kuntze, L. Börner, A. Wobus, U. Röder, M. S., Sreenivasulu, N. (2011). Haplotyping, linkage mapping and expression analysis of barley genes regulated by terminal drought stress influencing seed quality. BMC Plant Biology, 4: 1.

\section{How to cite this article:}

Aparjot Kaur and Thind, S.K. 2018. Cytokinin Application Retains Water Status and Carbohydrate Content of Wheat Genotypes under PEG-6000 Induced Water Deficit. Int.J.Curr.Microbiol.App.Sci. 7(08): 746-757. doi: https://doi.org/10.20546/ijcmas.2018.708.082 